\title{
Complicações tardias do uso de abraçadeiras de náilon para ligadura de pedículos ovarianos em cadela: relato de caso
}

\author{
[Late complications of the use of nylon clamp for ovarian pedicles ligation in a bitch: case report]
}

\section{"Relato de Caso/Case Report"}

\author{
Sabrina Cândido Trajano*, Grazielle Anahy Sousa Aleixo, Robério Silveira Siqueira Filho, \\ Mauro Araújo Penaforte Júnior, Lilian Sabrina Silvestre Andrade, \\ Angélica Costa Ferreira Souza, Thabata Morales Vieira Melo, Vanessa Sacramento Melo
}

Departamento de Medicina Veterinária, Universidade Federal Rural de Pernambuco (UFRPE), Recife-PE, Brasil. *Autor para correspondência/Corresponding author: E-mail: sabrina-vetbio@ hotmail.com

\begin{abstract}
Resumo
A ovariosalpingohisterectomia (OSH) é o procedimento cirúrgico mais realizado no sistema reprodutor da fêmea de cadelas e gatas, seja como cirurgia eletiva, visando evitar crias indesejáveis, ou ainda como medida terapêutica para pacientes portadoras de piometra, tumores influenciados pelos hormônios reprodutivos ou outras afecções. Como alternativa à técnica cirúrgica tradicional que utiliza fios de sutura para realizar a ligadura dos pedículos ovarianos e uterino, alguns cirurgiões tem utilizado abraçadeira de náilon, visando reduzir o tempo cirúrgico e diminuir os custos da cirurgia. No entanto, este dispositivo pode causar complicações graves, como granuloma e aderências. Diante disso, foi objetivo deste trabalho relatar complicações tardias após a realização de OSH eletiva em uma cadela em decorrência da utilização de abraçadeira de náilon para ligar os pedículos ovarianos. Uma cadela, foi atendida na Universidade Federal Rural de Pernambuco (UFRPE) apresentando vômito crônico e emagrecimento progressivo. Posteriormente a paciente foi encaminhada para celiotomia exploratória, onde foi possível identificar a formação de granulomas (em topografia de coto ovariano) e aderências decorrentes de ligaduras com abraçadeira de náilon em OSH realizada quatro anos antes. Concluiu-se que apesar do uso da abraçadeira tornar a técnica mais facilmente exequível e reduzir os custos da cirurgia, o seu emprego pode levar a complicações graves, como a formação de aderência e granulomas.
\end{abstract}

Palavras-Chave: granuloma; aderência; lacre de náilon; castração.

\begin{abstract}
Ovariosalpingohisterectomy (OSH) is the most performed surgical procedure in the female reproductive system of bitches and cats, either as elective surgery, aimed at avoiding unwanted pups, or as a therapeutic measure for patients with pyometra, tumors influenced by reproductive hormones or other conditions. As an alternative to the traditional surgical technique that uses suture threads to perform the ligation of the ovarian and uterine pedicles, some surgeons have used a nylon clamp, aimed at reducing surgical time and reducing surgery costs. However, this device can cause serious complications such as granuloma and adhesions. Therefore, it was the objective of this study to report late complications after elective OSH in a dog due to the use of a nylon clamp to connect the ovarian pedicles. A female dog was treated at the Universidade Federal de Pernambuco (UFRPE) with chronic vomiting and progressive weight loss. The patient was then referred for exploratory celiotomy, where it was possible to identify the formation of granulomas (in ovarian stump topography) and adherences due to ligatures with nylon clamp in OSH performed four years earlier. It is concluded that despite the use of the bracket make the technique more easily feasible and reduce the costs of surgery, that its use can lead to serious complications such as formation of adhesion and granulomas.
\end{abstract}

Key-words: granuloma, adhesion, nylon clamps, castration. 


\section{Introdução}

As abraçadeiras de náilon autoestáticas são dispositivos utilizados em instalações hidroelétricas na substituição de cabos e fios com a finalidade de agilizar o trabalho manual, sem perder a segurança (Barros et al., 2009). Elas são flexíveis e elásticas, possuem um guia autotravante e são altamente resistentes ao degaste e tração (Figura 1). Também suportam temperaturas que variam de $-40^{\circ} \mathrm{C}$ a $260^{\circ} \mathrm{C}$ sem perder suas propriedades físicas e químicas, o que permite a sua esterilização em autoclave (Barros et al., 2009).

Devido às características de segurança e economia proporcionadas pela abraçadeira de náilon, seu uso vem sendo empregado como método alternativo na hemostasia em ovariosalpingohisterectomia ( $\mathrm{OSH})$ em gatas e cadelas e ovariectomia (OE) em éguas (Costa Neto et al., 2009; Lustosa e Medeiros, 2014; Silva et al., 2007), em orquiectomia em cães (Hoglund, 2014), equinos (Silva et al., 2006), bovinos (Silva et al., 2009), caprinos (Costa Neto et al., 2014) e em ressecções hepáticas, pulmonares e esplênicas, assim como em cirurgias ortopédicas associado a pinos intramedulares, como substituto do fio de aço na cerclagem (Angelim et al., 2012; Miranda et al., 2006) e na redução de fratura umeral em aves (Nicolino et al., 2008).

A OSH é o procedimento cirúrgico mais realizado na medicina veterinária, seja como terapia para afecções do sistema reprodutor da fêmea ou para esterilização eletiva de gatas e cadelas com o objetivo de impedir a reprodução (Fossum, 2014; Van Goethem et al., 2006). Ainda é indicada na prevenção ou tratamento de tumores influenciados pelos hormônios reprodutivos (ex. hiperplasia mamária) além de auxiliar na estabilização de doenças sistêmicas (ex. epilepsia) e problemas de pele (ex. demodicose) (Fossum, 2014).

Diversos materiais podem ser utilizados para ligadura dos pedículos e corpo uterino, incluindo fios de sutura absorvíveis e não absorvíveis, clipes de titânio, abraçadeiras de náilon (Lustosa et al., 2014), anel de látex (Silva et al., 2006) ou hemostasia pela utilização de eletrocoagulação monopolar ou bipolar (Nimwegen e Kirpensteijn, 2007).

Embora a OSH seja considerada um procedimento simples, a mesma não está livre de complicações. Algumas são facilmente tratáveis, no entanto outras podem resultar em comprometimento do bem-estar do paciente ou até mesmo em seu óbito. As complicações mais comuns incluem hemorragias, infecções da ferida cirúrgica, síndrome do ovário remanescente, piometra de coto uterino (Adin, 2011), formação de granuloma, ligadura de ureter, incontinência urinária, formação de tratos fistulosos e obstruções intestinais (Holt et al., 2006; Kuan et al., 2010).

Diversos trabalhos têm sido realizados no Brasil e no exterior mostrando os benefícios do uso de abraçadeiras de náilon em OSH de gatas e cadelas, não sendo relatadas complicações no trans e no pós-cirúrgico, no entanto os resultados apresentados foram de pesquisas realizadas à curto prazo, com avaliações de até 90 dias após a implantação da abraçadeira (Costa Neto et al., 2009; Lustosa e Medeiros, 2014).

Diante das informações descritas, este trabalho tem como objetivo relatar o caso de uma cadela da raça Dachshund que apresentou complicações graves, quatro anos após a realização de uma cirurgia de OSH na qual foram utilizadas abraçadeiras de náilon para realizar as ligaduras dos pedículos ovarianos.

\section{Descrição do Caso}

Foi atendido no Hospital Veterinário da Universidade Federal Rural de Pernambuco (HV/UFRPE) uma cadela da raça Dachshund, castrada, com 10 anos de idade, pesando $5,4 \mathrm{~kg}$, com histórico de vômito recorrente e perda de peso progressiva há três meses. Anteriormente a cadela foi diagnosticada com babesiose associada à erliquiose, e tratada com dipropionato de imidocarb injetável associada a cloridrato de doxiciclina por via oral. O tratamento foi interrompido com poucos dias, pois a cadela vomitava após a administração de doxiciclina. De acordo com o tutor do animal, a cadela se alimentava e bebia água normalmente, no entanto apresentava episódios de vômito após as refeições, que com o passar do tempo, tornaram-se mais frequentes. O mesmo também relatou que a cadela foi submetida à OSH eletiva quatro anos antes.

Ao exame físico da paciente, notou-se caquexia, apatia, e pelos opacos, desidratação grau 2 e dor abdominal. Como exames complementares foram solicitados hemograma, perfil hepático e renal, urinálise, relação proteína/creatinina (RPC), ultrassom abdominal e radiografia simples e contrastada da região cervicotorácica.

Após avaliação e resultados dos exames, a paciente foi encaminhada para o setor cirúrgico, onde foi realizada uma celiotomia exploratória. 
Como protocolo pré-anestésico, foi utilizada associação de acepromazina $(0,025 \mathrm{mg} / \mathrm{kg})$ e tramadol $(2 \mathrm{mg} / \mathrm{kg})$ por via intra-muscular (IM). Foi administrado por via intravenosa (IV) cefalotina (30 $\mathrm{mg} / \mathrm{kg})$ como medida profilática antimicrobiana 30 minutos antes do procedimento cirúrgico. A indução anestésica foi realizada com propofol $(2 \mathrm{mg} / \mathrm{kg} / \mathrm{IV})$ e diazepam $(0,3 \mathrm{mg} / \mathrm{kg} / \mathrm{IV})$ e a manutenção anestésica com isoflurano em sistema inalatório semi-aberto.

Depois da cirurgia a paciente foi encaminhada para o internamento, onde foram recomendadas fluidoterapia, limpeza da ferida cirúrgica e administração de medicações (cefalotina $25 \mathrm{mg} / \mathrm{kg} / \mathrm{IV}$ ) a cada 12 horas (BID); metronidazol $15 \mathrm{mg} / \mathrm{kg} / \mathrm{IV} / \mathrm{BID}$; meloxicam 0,1 $\mathrm{mg} / \mathrm{kg}$ pela via subcutânea (SC), a cada 24 horas (SID) e ranitidina $2 \mathrm{mg} / \mathrm{kg} / \mathrm{IV} / \mathrm{BID}$ ). Como medicações pós-operatória foram prescritos os antibióticos Cefalexina (25 mg/kg/VO/BID) e metronidazol (15 mg/kg/VO/BID), o analgésico tramadol (3 $\mathrm{mg} / \mathrm{kg} / \mathrm{VO} / \mathrm{TID})$, entretanto a paciente foi à óbito quatro dias após a cirurgia.

\section{Discussão}

O lacre de náilon foi utilizado no caso descrito para realizar as ligaduras dos pedículos ovarianos de uma cadela submetida a OSH, em substituição aos fios de sutura. Tanto os fios de sutura absorvíveis como os fios não absorvíveis, assim como os lacres podem gerar uma reação inflamatória local (Barros et al., 2009). Porém se acredita que a reação à abraçadeira de náilon costuma ser maior do que aquela observada com o uso de fios de sutura, pois de acordo com Batista et al., 2002, a reação inflamatória é proporcional a espessura do material utilizado, então quanto mais calibroso, maior e mais intensa é essa resposta.

O granuloma seria o resultado final da inflamação crônica e geralmente está relacionado ao uso de material não absorvível nas ligaduras dos pedículos ovarianos e corpo do útero (Crowe Jr. e Bjorling 1998), como no caso descrito, onde o material utilizado (lacre) era de náilon, um produto não absorvível.

Exames complementares como eritrograma e dosagem de ureia, creatinina, fosfatase alcalina, e relação proteína/creatinina urinária estavam dentro dos padrões fisiológicos para a espécie. $\mathrm{Na}$ urinálise, a urina estava ligeiramente turva e com contagem bacteriana alta e o leucograma apresentou leucocitose, sugerindo cistite bacteriana.
No exame ultrassonográfico foi observado: jejuno com parede espessada, peristaltismo aumentado e conteúdo sólido e gasoso; aumento de ecogenicidade mesentérica em região lateral esquerda, ventral ao rim esquerdo; linfonodos mesentéricos aumentados na região lateral esquerda; fígado com dimensões levemente aumentadas e ecogenicidade diminuída; rim esquerdo com achados ecográficos mal definidos da região corticomedular e cápsula irregular; presença de nodulação ecogênica em região medular, delimitada, com formato arredondado sugestivo de neoplasia ou hiperplasia e estômago com peristaltismo mantido, com parede espessada em seu maior diâmetro e bexiga urinária com parede ventral espessa.

No exame radiográfico não foram visualizadas alterações no percurso esofágico no exame simples e no exame contrastado, não ocorrendo retenção da linha de contraste, descartando a suspeita clínica de obstrução esofágica.

Durante a cirurgia foram observadas duas reações granulomatosas em topografia de pedículos ovarianos. Foi removida uma abraçadeira de náilon fortemente aderida ao granuloma do pedículo ovariano direito (Figura 1) e à palpação foi possível localizar o outro granuloma do lado esquerdo, onde se pode sentir uma estrutura firme em seu interior, semelhante a uma abraçadeira de náilon, compatível com o achado ultrassonográfico.

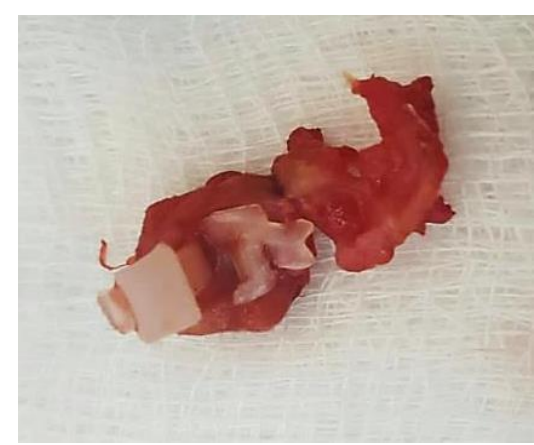

Figura 1. Abraçadeira de náilon encontrada dentro do granuloma do pedículo ovariano direito de uma cadela.

Não foi possível realizar a ressecção do segundo granuloma pelo fato do mesmo se encontrar fortemente aderido ao rim esquerdo. Neste caso, seria necessário realizar uma nefrectomia associada, o que foi desencorajado, pelo fato do órgão se encontrar macroscopicamente saudável, além de a paciente não apresentar alteração na função renal de acordo com os exames, 
sugerindo que o granuloma não estava causando alteração na função do órgão. Durante a celiotomia exploratória não foi observada alteração em coto uterino.

Além dos dois granulomas, foi visualizada intensa aderência fibrosa entre estômago, pâncreas, aorta abdominal, omento, intestino delgado e cólon (Figura 2) que foram liberados por adesiólise após um procedimento laborioso, levando em consideração a quantidade de aderências presentes. Também foram realizados gastrorrafia $\mathrm{e}$ enterorrafia utilizando fio absorvível de polidioxanona 2,0 seguida da omentalização do estômago e do intestino.

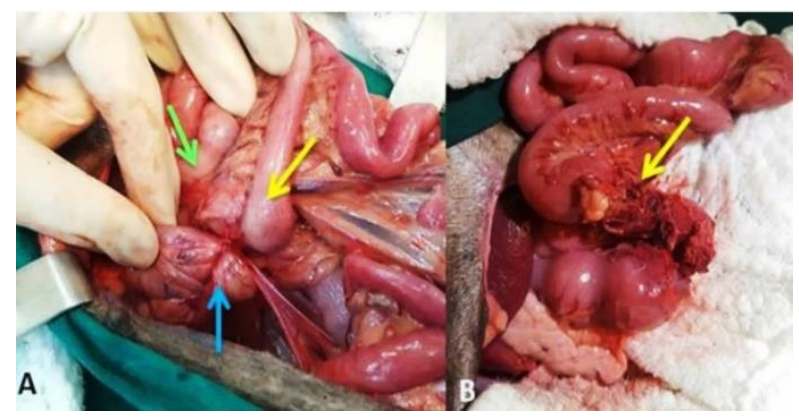

Figura 2. Aderência intra-abdominal em cadela. (A) Observar aderência entre intestino delgado (seta amarela), estômago (seta verde) e omento (seta azul). (B) Observar o estômago após a adesiólise (seta amarela).

A origem do granuloma e das aderências no caso relatado, provavelmente foram devido ao uso da abraçadeira de náilon nas ligaduras dos pedículos ovarianos, assim como foi observado em outros casos descritos por Macedo et al., 2012 e Mesquita et al., 2015. Alguns autores vêm provando que o uso de abraçadeiras de náilon propicia a aderência de bactérias contribuindo para a persistência e progressão da infeção, além dos fatores biológicos do próprio paciente, favorecendo a formação de granulomas (Van Goethem, 2006), como observado na paciente relatada onde a leucocitose sugestiva de cistite bacteriana pode também estar associada ao uso da abraçadeira de náilon e consequente, formação do granuloma.

Em estudo realizado por Atallah et al. (2013), as complicações pós-operatórias surgiram com até oito anos após a realização do procedimento cirúrgico de $\mathrm{OSH}$ utilizando material não absorvível, um período bastante longo e que dificulta a relação do diagnóstico com a cirurgia. $\mathrm{O}$ mesmo ocorreu com a paciente relatada, pois a mesma foi encaminhada para vários veterinários $\mathrm{e}$ diversos diagnósticos foram sugeridos, entre eles babesiose, ingestão de corpo estranho e neoplasia intra-abdominal, sendo necessário realizar cirurgia exploratória do abdômen em busca de um diagnóstico definitivo.

Macedo et al. (2012) relataram complicações associadas ao uso de abraçadeira de náilon em OSH em cadelas, onde reações granulomatosas envolta dos lacres e formação de fístula. No caso relatado, não foi observado presença de fístula apesar do intenso processo inflamatório instalado na cavidade.

Os sinais clínicos podem surgir num período que varia de poucos meses a anos após a realização da cirurgia (Macedo et al. 2012; Mesquita et al. 2015), e varia de acordo com a área cometida. A paciente do caso relatado apresentava vômito recorrente e perda de peso progressiva, pois o estômago e parte do intestino da cadela estavam aderidos ao granuloma.

Em decorrência de complicações póscirúrgicas tardias, o Conselho Federal de Medicina Veterinária (CFMV) emitiu um parecer técnico científico contra indicando o uso de abraçadeiras de náilon em $\mathrm{OSH}$ e $\mathrm{OE}$ em pequenos animais, uma vez que o dispositivo pode apresentar risco em longo prazo, como a formação de granulomas e fístulas (CFMV, 2015). Recomenda-se o uso de materiais menos adesiogênicos como fios de náilon, ácido poliglicólico, poliglactina 910 e polidioxanona (Boothe 1998), materiais esses, utilizados na rotina do Hospital Veterinário da UFRPE para realizar castrações cirúrgicas.

A abraçadeira de náilon não é comercializada por indústrias farmacêuticas, não estando regulamentado o seu uso em animais, não possui embalagem própria e não é comercializado sob condições estéreis, sendo responsabilidade do Médico Veterinário garantir sua esterilização (CFMV, 2015), o que reforça a contraindicação em utilizar esse dispositivo.

Abraçadeiras absorvíveis estéreis de polidioxanona estão sendo produzidas por indústrias farmacêuticas regulamentadas, porém ainda não estão disponíveis no Brasil. Tais produtos podem elevar o valor do procedimento cirúrgico, mas provavelmente proporcionarão os benefícios de redução de tempo cirúrgico e segurança nas ligaduras, além de diminuir a ocorrência de complicações cirúrgicas (Hogglund et al., 2014).

De acordo com Santos et al. (2009), o tratamento das aderências consiste de adesiólise dos órgãos e tecidos adjacentes envolvidos, o que foi realizado por meio da divulsão utilizando 
tesouras cirúrgicas de ponta rompa e manobras de tracionamento manual. $\mathrm{O}$ procedimento de adesiólise foi laborioso e demorado em decorrência da aderência de diversos órgãos, como descrito acima, e o envolvimento de estruturas anatômicas extremamente importantes, tais como o pâncreas e a aorta abdominal.

\section{Conclusão}

A abraçadeira de náilon ocasiona complicações tardias em uma cadela submetida a $\mathrm{OSH}$, como a formação de granulomas e aderências fibrosas entre diversos órgãos abdominais, cuja severidade das alterações, resultou no óbito da paciente. Diante dos fatos, desaconselha-se a utilização de abraçadeira de náilon na realização de OSH em animais da espécie canina.

\section{Conflito de Interesse}

Os autores declaram não existir conflito de interesse.

\section{Referências}

Adin, C.A. Complications of ovariohysterectomy and orchiectomy in companion animals. Veterinary Clinico of Small Animals, 41: 1023-1039, 2011.

Angelim, J.L.; Costa-Neto, J.M.; Martins Filho, E.F.; Carneiro, R.L.; Ramos, C.S.; Araújo, M.S.C.; Neto, J.E. Avaliação de três métodos de aerostasia bronquial - Estudo experimenta em árvores traqueobrônquicas de suínos. Revista Brasileira de Medicina Veterinária, 34(4): 341-348, 2012.

Atallah, F.A.; Silva, R.S.; Ramos, M.L.M.; Oliveira, A.L.A.; França, T.N.; Brito, M.F. Complicações pós-cirúrgicas em cadelas submetidas a ovariohisterctomia no Rio de Janeiro. Revista Brasileira de Medicina Veterinária, 35: 61-69, 2013.

Barros, B. J.; Sanches, A. W. D.; Pachaly, J. R. Utilização de abraçadeira de náilon 6.6 (poliamida) como método de ligadura de pedículos ovarianos e coto uterino em ováriohisterectomia eletiva em cadelas (Canis familiaris). Arquivos de Ciências Veteterinárias e Zoologia, 12(1): 47-60, 2009.

Batista, F.C.; Batista, J.E.L.; Fronza, B.R. Características microscópicas de superfície de biocompatibilidade dos fios de sutura mais utilizados em cirurgia bucal. Revista
Brasileira de Cirurgia e Implantodontia, 9(35): 243-349, 2002.

Boothe, H.W. Materiais de sutura, adesivos teciduais, grampeadores e grampos de ligadura. In: Slatter, D. Manual de cirurgia de pequenos animais. 2. ed. São Paulo: Manole, 1998. 253-263p.

CFMV. Conselho Federal de Medicina Veterinária. Serviço Público Federal. Uso de abraçadeira de nylon. Brasília, 2015. 5p.

Costa Neto, J.M.; Teixeira, E.M.; Ferreira Filho, E.M.; Toríbio, J.M.M.L.; Almeida Filho, C.H. R.; Moraes, V.J. Braçadeiras de náilon para hemostasia preventiva na ovariosalpingohisterectomia em gatas. Revista Brasileira de Saúde e Produção Animal, 10(3): 615- 624, 2009.

Costa Neto, J.M.C.; Guimarães, J.E.; Oriá, A.P.; Conceição Junior, D.G.; Sacramento, T.G. Emprego da abraçadeira de náilon na orquiectomia de caprinos. Enciclopédia Biosfera, 10(18): 1508, 2014.

Crowe J.R., D.T.; Bjorling D.E. Peritôneo e cavidade peritoneal. In: Slatter D. Manual de cirurgia de pequenos animais. 2. ed. São Paulo: Manole, 1998. 499-526 p.

Fossum, T. W. Cirurgia dos sistemas reprodutivo e genital. In: Cirurgia de pequenos animais. 4. ed. Rio de Janeiro: Elsevier. 2014. Cap.27, 780-867 p.

Hoglund, O.V.; Ingman, J.; Soderstein, F.; Hansson, K.; Borg, Niklas.; Lagerstedt, AnneSofie. Ligation of the spermatic cord in dogs with a self-locking device of a resorbable polyglycolic based co-polymer - feasibility and long-term follow-up study. BMC Research Notes, 7(825): 2014.

Holt, P.E.; Bohannon, J.; Day, M.J. Vaginoperitoneal fístula after ovarysterectomy in three bitches. Journal Small Animal practice, 47: 744-746, 2006.

Kuan, S.Y.; Ticehurst, K.; Hoffman, K.L.; Crosby, D.; Barrs, V.R. Intestinal strangulation after elective ovariohysterectomy. Jounal of Feline Medicine and Surgery, 12(4): 325329, 2010.

Lustosa, L.S.C.; Medeiros, M. Abraçadeira de náilon em ovariosalpingohisterectomia em cadelas. Revista Cientifica de Medicina Veterináira, 1(1): 2014.

Macedo, Al.S.; Dal-Bó, I.S.; Quadros, A.M.; Brambatti, G.; Reis, K.D.H.L.; Brun, M.M.A; Beck, C.A. Complicações associadas à 
ovariosalpingohisterectomia eletiva realizada com abraçadeira de náilon como método de hemostasia. Acta Scientiae Veterinariae, 40(4): 1086, 2012.

Mesquita, L.R.; Rahal, S.C.; Matsubara, L.M.; Mamprim, M.J.; Foschini, C.R.; Faria, L.G.; Kano, W.T. Bilateral hydronephrosis and hydroureter after ovariohysterectomy using nylon cable tie: a case report. Veterinarni Medicina, 60(1): 52-56, 2015.

Miranda, A.F.; Silva, L.A.F.; Tavares, G.A.; Amaral, A.V.C.; Miranda, H. G. Abraçadeiras de náilon: resistência à tração em testes físicos e seu emprego como cerclagem no fêmur de cães. Ciência Animal Brasileira, 7(3): 299307, 2006.

Nicolino, R.R.; Accetta, J.L.; Ferreira, J.C. Utilização da abraçadeira de nylon em redução de fratura de úmero em carcará (Caracara plancus): relato de caso. In: XI CONGRESSO - XVII ENCONTRO ENCONTRO DA ASSOCIAÇÃO BRASILEIRA VETERINÁRIOS DE ANIMAIS SELVAGENS, 11., 2008, São Paulo, Anais... São Paulo, Abravas: 2008. 136-138 p.

Nimwegen, S.A.; Kirpensteijn, J. Laparoscopic ovariectomy in cats: comparison of laser and bipolar electrocoagulation. Jounal of Feline Medicine e Surgery, 9(5): 397-403, 2007.
Santos, F.C.; Corrêa, T.P.; Rahal, S.C.; Crespilho, A.M.; Lopes, M.D.; Mamprim, M.J. Complicações da esterilização cirúrgica de fêmeas caninas e felinas. Revisão de Literatura. Veterinária e Zootecnia, 16(1): 8-18, 2009.

Silva, L.A.F.; França, R.O.; Vieira, D.; Souza, V. R.; Franco, L.G.; Moura, M. I; Silva, M.A.M.; Trindade, B.R.; Costa, G.L.; Bernardes, K.M. Emprego da abraçadeira de náilon na orquiectomia em equinos. Acta Scientiae Veterinariae, 34(3): 261-266, 2006.

Silva, L.A.F.; França, R.O.; Vieira, D.; Garcia, A. M.; Moura, M.I.; Silva, M.A.M.; Silva, E.B.; Trindade, B.R.; Franco, L.G. Emprego da abraçadeira de náilon, do categute e do emasculador na hemostasia preventiva de ovariectomia em éguas. Ciência Animal Brasileira, 8(1): 135-146, 2007.

Silva, L.A.F.; Costa, A.C.; Soares, L.K.; Borges, N.C.; Ferreira, J.L.; Cardoso, L.L. Orquiectomia em bovinos empregando abraçadeira de náilon na hemostasia preventiva: efeito da estação do ano, método de contenção e técnica cirúrgica. Ciência Animal Brasileira, 10(1): 261-270, 2009.

Van Goethem, B.; Okkens-Schaefers, A.; Kirpensteijn, J. Marking a rational choice between ovariectomy and ovariohysterectomy in the dog: a discussion of the benefits either techique. Veterinary Surgery, 35: 136-143, 2006. 